\title{
Mesenchymal Stem Cell-Like Properties in Fibroblasts
}

\author{
Yuqiao Chang ${ }^{\mathrm{a}, \mathrm{b}}$ He Lia Zhikun Guo \\ aDepartment of Human Anatomy and Embryology, Tongji Medical College, Huazhong University of \\ Science and Technology, Wuhan, ${ }^{b}$ Key Laboratory for Medical Tissue Regeneration of Henan Province, \\ Xinxiang Medical University, Xinxiang, China
}

\section{Key Words}

Fibroblasts • Mesenchymal stem cells • Directed differentiation • Epithelial-mesenchymal transition - Mesenchymal to epithelial transition

\begin{abstract}
Fibroblasts are biologically dynamic and morphologically heterogeneous and are the most abundant connective tissue cells, with diverse structures depending on their location and activity. The main function of fibroblasts is to maintain the structural integrity of connective tissues by continuously secreting precursors of the extracellular matrix. Recent advances in our knowledge on pathophysiologic features of fibroblasts revealed that in some situations epithelial cells can give rise to fibroblasts by epithelial-mesenchymal transition (EMT) and conversely, in some other situations, fibroblasts may give rise to epithelia by undergoing a mesenchymal to epithelial transition (MET). Given an opportunity to differentiate to other cells, fibroblasts may foster a novel clue for in situ tissue repair and contribute to cellular mechanisms of mesenchymal stem cell-like features under normal or pathological conditions. They have also been shown to suppress immune responses in vitro. Because of these properties, fibroblasts have recently received a very high profile in the literature. This review summarizes our understanding of the origins, mesenchymal stem cell-like characteristics and potency of directed differentiation of fibroblasts. In addition, we also present the evidence that mesenchymal stem cells and fibroblasts share much more in common than previously recognized.
\end{abstract}




\section{Introduction}

Fibroblasts are the most common type of cells found in connective tissue. Fibroblasts secrete collagens that are used to maintain a structural framework for many tissues. They also play an important role in healing wounds. During the process of the chronic diseases or during normal aging, all kinds of tissues and organs undergo fibrosis gradually, such as fibrosis of skin, lung, liver, kidney and heart etc., which can severely impair our health. Fibrosis is also closely related to proliferation of fibroblasts. Fibroblasts secrete excessive extracellular matrix and collagens during proliferation and thereby replace normal organ structure, leading to functional impairment and scar formation, which may further trigger persistent fibrosis [1, 2].

Fibroblasts have classically been viewed as a uniform cell type with equivalent functions regardless of the origins of tissue $[3,4]$. This view has been challenged by data illustrating extensive phenotypic heterogeneity among fibroblasts from different tissues and from a given tissue under different physiologic conditions [5]. Indeed, lung fibroblasts have been shown to be heterogeneous in cell surface marker expression, as well as in their levels of collagen production [6]. Moreover, periodontal fibroblasts also show heterogeneity based on morphology, glycogen pools, and collagen production [7]. Additionally, fibroblasts from different anatomic sites have distinct transcriptional patterns [8]. Under appropriate stimulation, relatively quiescent fibroblasts can acquire an active synthetic, contractile phenotype and express several smooth muscle cell markers, which are not exclusive for fibroblasts [9].

Human hypertrophic scar-derived fibroblasts show the biologic characteristics of mesenchymal stem cells [10]. Multidirectional differentiation induction indicated that the fibroblasts could differentiate into adipogenic, osteogenic and chondrogenic lineages [1113]. Scientists pay close attention to their function in repair of pathological injury. Despite the dramatic benefits reported in early phase clinical trials, their functions remain poorly understood. Particularly, several questions remain unanswered concerning the origin of mesenchymal stem cells and their relationship to other stromal cells such as fibroblasts. In the following sections, we summarize current insights into fibroblasts origin and their distribution, molecular markers, as well as characteristics of mesenchymal stem cells and potency of directed differentiation, and highlight emerging hypotheses and targets for further research.

\section{Origin and distribution}

Originally, fibroblasts were described in late 19th century based solely on their location and morphological criteria [14, 15]. Fibroblasts are typically identified by their spindleshaped flattened morphology, ability to adhere to culture plates, and in general they lack a basement membrane and tend to have multiple processes or sheet-like extensions. They contain an oval nucleus (with 1 or 2 prominent nucleoli), extensive rough endoplasmic reticulum, a prominent Golgi apparatus, and abundant cytoplasmic granular material. In all tissues, fibroblasts are usually adherent to the fibers which they themselves lay down and thus can form a three-dimensional (3-D) network and become embedded within the fibrillar extracellular matrix (ECM) $[14,16]$. Fibroblasts synthesize most of the ECM of connective tissues, including interstitial collagens, proteoglycans, glycoproteins, cytokines, growth factors, and proteases [17]. These components form an elaborate 3-D network that is intimately associated with structure and function [18].

Fibroblasts serve diverse vital distribution during different development states, various organs and different locations. For example, cardiac fibroblasts (CFs) are the predominant cell type in number, but the cardiac myocytes actually occupy the greatest volume $[19,20]$. CFs are found throughout the heart in a 3-D network surrounding myocytes and bridging the gaps between myocardial tissues [16, 21]. Myocytes are arranged in laminae bounded 


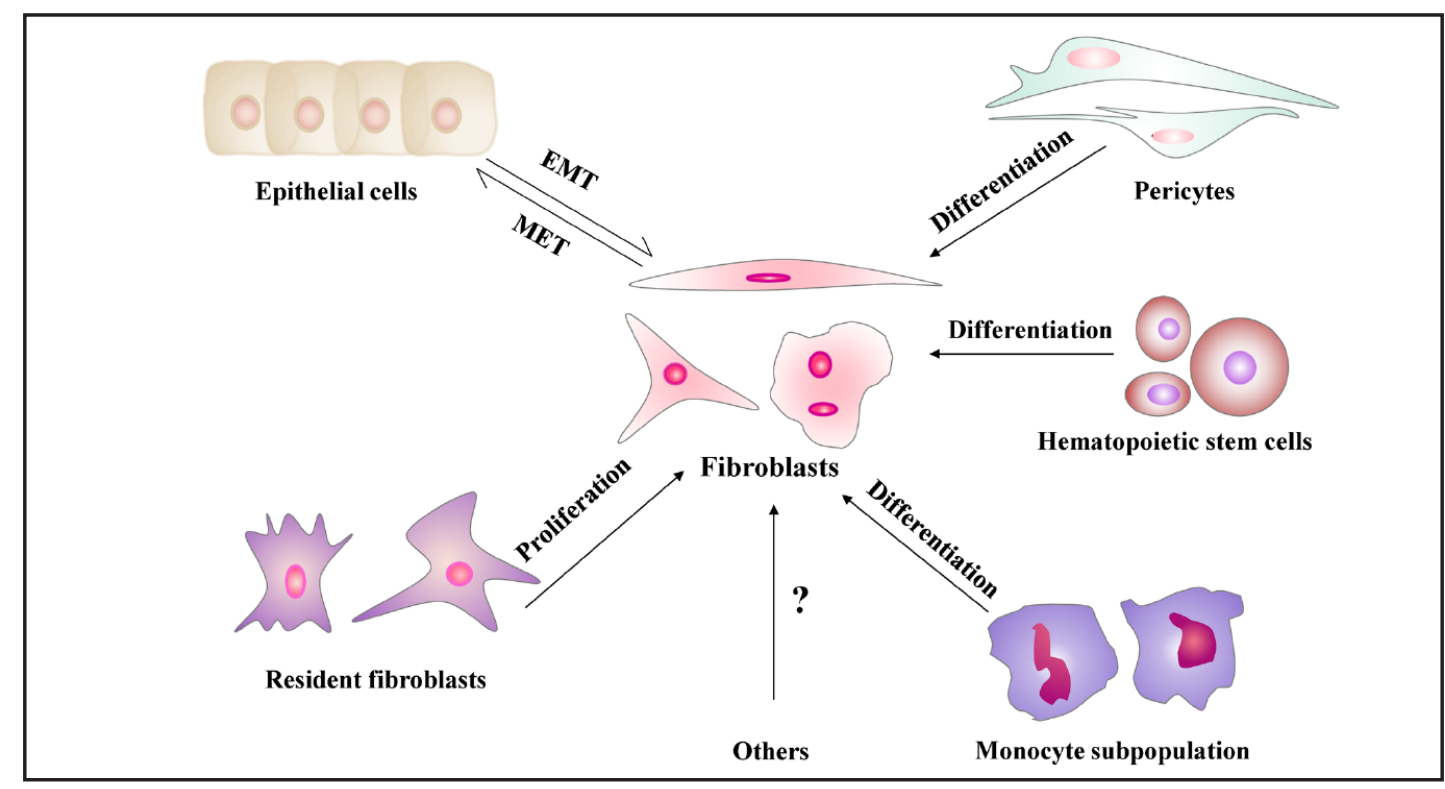

Fig. 1. The possible origin of the fibroblasts. The sources of fibroblast include (1) resident fibroblasts division; (2) epithelial cells through EMT pathway, fibroblasts in some situations may give rise to epithelia by undergoing MET pathway; (3) hematopoietic stem cell origin; (4) pericytes can contribute to the adult interstitial fibroblast population; (5) monocyte subpopulation can migrate into the damaged parts and differentiate into fibroblasts; (6) others have not been recognized.

by endomysial collagen, and CFs lie within this endomysial network [22]. CFs appear coincidentally with ventricular compaction around embryonic of day 12.5 and increase in number steadily through postnatal day one in mouse [23]. CFs have been recently shown to play an important role in proliferation during development of heart. The mammalian heart undergoes a major change in physiological pressures to transition from a fetal to neonatal circulation. Cessation of flow through the ductus arteriosus and increased pulmonary return cause an elevation of ventricular pressure. A robust CF response to the increased neonatal circulatory demands is seen during the first two neonatal weeks when the CF population increases from $10 \%-20 \%$ to $70 \%$ within a relatively short time [24]. Most studies agree that the first 2 weeks of murine cardiac growth result in at least a doubling of the CF population. However, there is a paucity of reports regarding the relative CF makeup of the adult heart. Early studies on adult rat left ventricle estimated that $65 \% \sim 70 \%$ of the cells were noncardiomyocytes $[25,26]$, whereas recent studies analyzing the total mouse heart by FACS and confocal microscopy estimate a much higher number of cardiomyocytes at $\sim 56 \%$ and $\sim 44 \%$ nonmyocyte content, with only $27 \%$ of them are fibroblasts. The densest population of CFs in healthy adult hearts is found around the sinoatrial node $[27,28]$, thus providing complete electrical insulation. It remains unclear whether CFs are evenly distributed throughout the developing heart and whether they emerge via a uniform or clustered spatiotemporal manner.

Despite the identification of fibroblasts in the late 19th century and the advent of elegant lineage mapping tools such as DiI labeling, zebrafish photoactivatable (caged) fluorescein marking, and murine loxP/Cre recombinase-mediated genetic cell-marking techniques, relatively little is known about the origin and development of the fibroblasts. Combining the existing domestic and overseas research results, fibroblasts have different origins at different developmental stages. Fibroblasts are traditionally defined as cells of mesenchymal origin (Fig. 1). The mesenchymal cells that form the fibroblast population are believed to be derived from the EMT. Epithelia cells lose their special molecular markers, such as E-cadherin or zonaoccludens-1, and express the proteins of fibroblasts (fibroblast 
Chang/Li/Guo: Multipotential Differentiation Capacity of Fibroblasts

Table 1. molecular markers for fibroblasts or myofibroblasts

\begin{tabular}{ll}
\hline Molecular markers & Cell types expressed \\
\hline \multirow{2}{*}{ vimentin } & fibroblasts ; telocytes; pancreatic precursor cells; endothelial cells; neurones; \\
& sertoli cells; macrophages; neutrophils; leukocytes; mesangial cells; various \\
& epithelial cancer cells \\
& fibroblasts; osteocytes; leukocytes; tumor cells \\
DDR2 & fibroblasts; neuronal cells; bone marrow stem cells; thymocytes; glomerular \\
& mesangial cells; T-lymphocytes \\
CD90/Thy1 & myofibroblasts; mesangial cells; vascular smooth muscle cells (VSMC); pericytes; \\
& visceral smooth muscle cells; kidney mesangial cells; liver stellate cells; lung \\
& interstitial cells \\
& fibroblasts; hematopoietic cells; endothelial cells; vascular smooth muscle cells; \\
& leukocytes; a multitude of cancer cells \\
FSP1 & myofibroblasts; myoepithelial cell; myoid cells \\
smooth muscle $\alpha$-actin & myofibroblasts
\end{tabular}

specific proteins, FSPs) during the process of EMT [29]. Then fibroblasts start to proliferate rapidly for the first several days of the postnatal life. Several studies have illustrated that increased fibroblasts are derived from resident fibroblast division or through EMT pathway. But some researches insist on their hematopoietic stem cell origin, and these multipotent progenitors have the ability to differentiate into a variety of vascular and mesodermal tissues [30]. A variety of studies in the adult suggests that fibroblasts increase slowly, derived from resident fibroblast division or through EMT pathway. Some research teams persist in the belief that progenitor cells, such as pericytes, adventitial cells associated with the vasculature, and mesenchymal stem cells of the bone marrow, can contribute to the adult interstitial fibroblast population [31,32]. It is conceivable that the proliferating, perivascular fibroblast population in the heart stems from bone marrow-derived circulating progenitors and the pro-epicardial organ $[18,33,34]$. So fibroblasts are thought to arise from various sources at different stages of development.

Fibroblasts start to proliferate rapidly during development and disease, such as cardiac hypertrophy, myocardial infarction (MI), idiopathic pulmonary fibrosis (IPF), kidney fibrosis, hypertrophic scar in skin, and so on, which eventually leads to organ fibrosis. Studies show that fibroblasts in pathological conditions have a wide variety of origins. The fibrosis process is similar in all organs to some degree. In addition to endogenous fibroblast proliferation, circulating monocyte subpopulations can migrate into the damaged parts and differentiate into fibroblasts. But some scientists presume that bone marrow-derived fibroblasts enter in the injured sites. So far, more and more studies afford evidence that EMT pathway is associated with the fibrosis process. Fibroblasts in some situations may give rise to epithelia by undergoing a mesenchymal to epithelial transition (MET). This process is seen in many developmental situations, as well as in wound healing and tumorigenesis. (http:// en.wikipedia.org/wiki/Fibroblast)

Taken together, these studies suggest that fibroblasts of various organs are likely to derive from hematopoietic stem cells, pericytes, mesenchymal cells through EMT pathway. But how fibroblasts are generated, which cytokines prompt their migration, transformation, and how cells move to reside in their final position, also remains to be elucidated more comprehensively.

\section{Molecular markers}

The lack of a reliable and specific fibroblast marker is a major limiting factor in the study of fibroblasts in vivo and is assuredly why they remain so poorly understood in 
both molecular and cellular terms $[14,15]$. A useful label for fibroblasts is anti-vimentin antibodies that react with the abundant intermediate filaments of fibroblasts [27]. But vimentin is also expressed in endothelial cells of capillaries that often locate very close to fibroblasts. This marker also labels neurons, which contain intermediate filaments (Table 1). Given the characteristic cyto-morphological differences between these cell types, however, anti-vimentin has been a suitable tool for reliable identification of fibroblasts.

More recently, a more specific marker for cardiac fibroblasts is the collagen receptor Discoidin Domain Receptor 2 (DDR2 [19]). DDR represents a relatively novel family of collagen specific receptor tyrosine kinases $[35,36]$. Receptor tyrosine kinases are a family of proteins involved in the conversion of extracellular stimuli into cellular responses [37]. These receptors mediate a variety of cell functions, including growth, migration, morphology and differentiation. The tissue distribution of DDR1 and DDR2 varies (and can be mutually exclusive), and DDR2 expression has been detected in both rat and mouse heart, as well as the isolated cardiac fibroblasts $[38,39]$. Originally defined as a collagen receptor on mesenchymal cells, DDR2 has also been found on leukocytes, as well as in tumors, but not on cardiomyocytes or cardiac endothelial and smooth muscle cells [19]. Interestingly, DDR2 gives a labeling pattern that is very similar to that obtained using vimentin antibodies [16].

Thy-1 (or CD90) is a small glycoprotein (25-30 kDa) anchored through a glycosylphosphatidylinositol (GPI) tail [40]. Thy-1 is expressed on several cell types: thymocytes, T-lymphocytes, bone marrow stem cells, neuronal cells, glomerular mesangial cells as well as fibroblasts of different origins (Table 1). Thy-1 expression on fibroblasts appears to be variable and seems to reflect the heterogeneity of this cell population [6]. Indeed, several groups have been able to isolate Thy $-1^{+}$and Thy-1- ${ }^{-}$fibroblasts from mouse and rat lungs or from human orbit and reproductive tract [41-44]. At best, scientists detected less than $10 \%$ of Thy $1^{-}$cells in primary culture of cardiac fibroblasts. This may represent contaminating cells. In addition, this level fell below 2\% in subsequent passages [45]. Unlike murine or rat lung fibroblasts, rat cardiac fibroblasts appear to form a homogeneous population with only Thy- $1^{+}$cells. Flow cytofluorometry revealed that the cells, at every passage, were positive for DDR2 or $\alpha 8$ integrin and Thy-1. Interestingly, the majority of cardiac fibroblast cells expressed high levels of all three antigens. Interestingly, Thy-1 heterogeneity seems to differently affect their proliferative and synthetic characteristics [46]. Thy- $1^{+}$lung fibroblast phenotype exhibits profibrogenic properties with enhanced collagen deposition [47], whereas the Thy-1- cell shows more apparent myofibroblastic features, particularly when the cells were stimulated with TGF- $\beta$ or connective tissue growth factor (CTGF) [48].

Another marker that has been proposed to be a fibroblast-specific marker is fibroblastspecific protein-1 (FSP1) [29, 49], however, other studies in the literature have shown that FSP1 is also expressed in a variety of other cell types, including leukocytes and a multitude of cancer cells [50]. It has also been shown that fibroblast-activation protein, a serine protease, is highly expressed on activated fibroblasts $[15,51]$.

$\alpha 8 \beta 1$ integrin, a cell adhesion receptor that links actin myofilaments to ECM proteins, is also detected on fibroblasts. It can not only mediate mechanical and chemical signals from the matrix, but also regulate cell differentiation, immunization and adhesion through bidirectional membrane transduction. However, it has been recently shown that $\alpha 8 \beta 1$ integrin is present not only on fibroblasts but also on vascular smooth muscle cells (VSMC) [52]. An interesting feature of cardiac fibroblasts is their ability to transform into myofibroblasts. The appearance of smooth muscle (SM) $\alpha$-actin-positive cytoplasmic myofilaments is often used to detect them, and as such SM $\alpha$-actin is now recognized as a reliable marker of the myofibroblast phenotype. Myofibroblasts also express a larger quantity of $\alpha 8 \beta 1$ integrin [52, 53].

The relatively specific molecular markers have been established gradually, which promotes further research on fibroblasts and improves our understanding of their function in normal and patho-physiological states. 


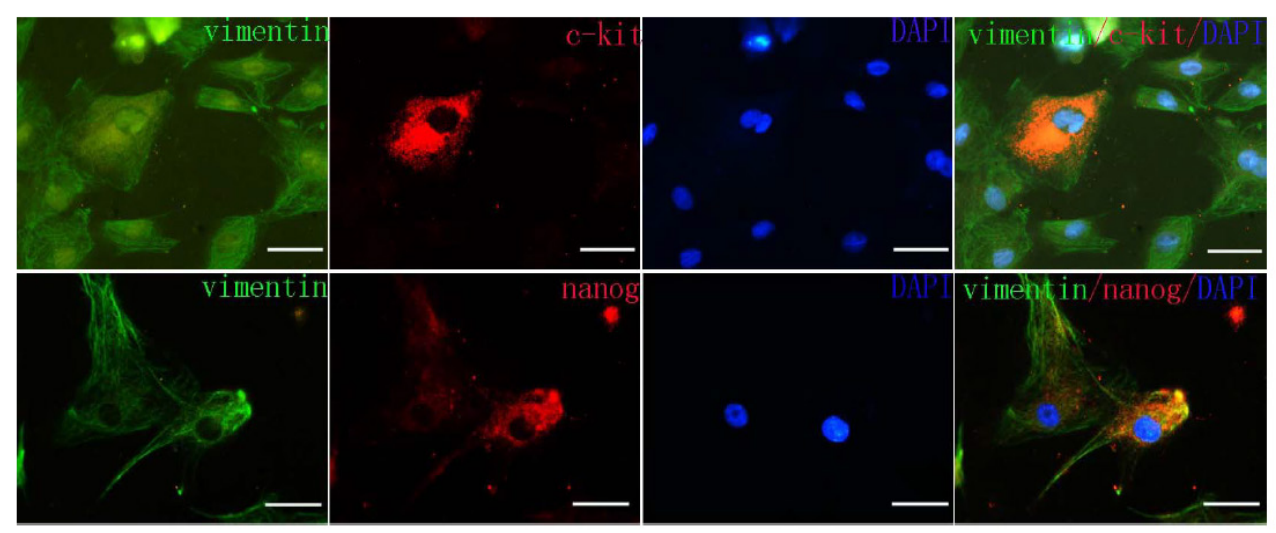

Fig. 2. Immunofluorescence staining of vimentin and stem cell markers (c-kit or nanog) in the cultured neonatal rat cardiac fibroblasts. A and E: general cell appearance revealed by vimentin immunostaining (FITC immunolabeling); B and F: c-kit or nanog expression in some fibroblasts (Cy3 immunolabeling); C and G: cell nuclei immunolabeled with DAPI (blue, florescent DNA dye); D: merge of A, B and C; H: merge of E, F and H. Scale bars: $50 \mu \mathrm{m}$.

\section{Characters of mesenchymal stem cell}

Mesenchymal stem cells (MSCs)are currently defined as plastic adherent, multipotential fibroblast-like cells expressing CD73, CD105 and negative for the hematopoietic markers CD14, CD34 and CD45 [54,55], but these properties and markers are also shared by fibroblasts.

Saeed et al. revealed that mouse embryonic fibroblasts(MEF) exhibited surface markers characteristic of the BMSC: Sca- $1^{+}, \mathrm{CD}_{3}{ }^{+}, \mathrm{CD} 105^{+}, \mathrm{CD} 29^{+}, \mathrm{CD} 44^{+}, \mathrm{CD} 106^{+}, \mathrm{CD} 11 \mathrm{~b}^{-}$, and CD $45^{-}$ [56]. Interestingly, compared to BMSC, MEF exhibited a more enhanced differentiation into adipocyte and chondrocyte lineages. Cultured fibroblasts can express the pluripotency marker genes Oct- $4[57,58]$, which is a homeodomain transcription factor of the POU family. This protein is critically involved in the self-renewal of undifferentiated embryonic stem cells. As such, it is frequently used as a marker for undifferentiated cells. Researchers have found that adult epidermal cells possess multipotent differentiation capacities of epidermal stem cells under injury stimulation and differentiate into epidermal cells, participating in wound healing.

Fibroblasts can express CD90, detected in many tissues, such as human myometrium, orbital cavity and lung. $\mathrm{CD}^{+} 0^{+}$fibroblasts in adult show stem cell characters and high immature potential. These cells are isolated and cultured in the early generations and have the potential to differentiate into other cell types. Our previous results have established that cardiac fibroblasts express nanog, which is also expressed in embryonic stem cells (ESCs) and is thought to be a key factor in maintaining pluripotency. In other words, these cells have the ability to become virtually any cell of any of the three germ layers (endoderm, ectoderm, mesoderm). Fibroblasts in the infarction border in $1 \mathrm{~W}$ myocardial infarction rats also express c-kit, one of the important members of tyrosine kinase receptor protein. c-kit plays an important role in cell differentiation and proliferation. We have the similar results in the cultured neonatal rat cardiac fibroblasts (Fig. 2).

In conclusion, fibroblasts in mouse embryonic, epidermis and heart have stem cell characteristics. It remains unknown whether fibroblasts in other organs can express stem cell markers. 


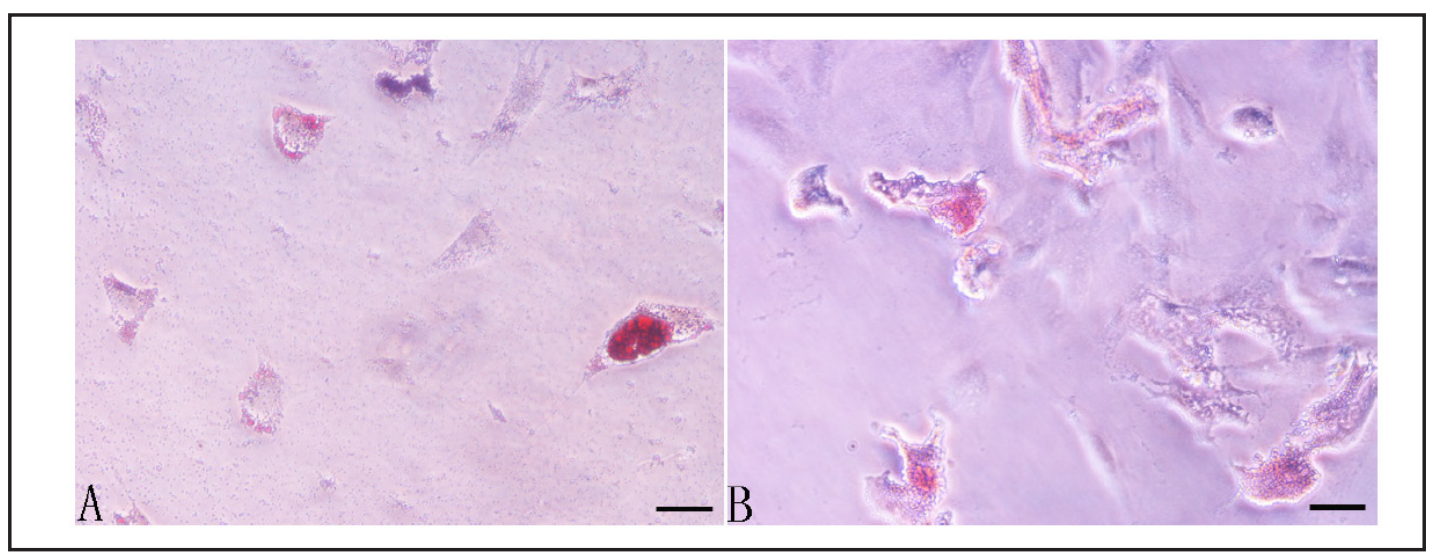

Fig. 3. Adipogenic and osteogenic differentiation of cultured neonatal rat cardiac fibroblasts. A: adipogenic differentiation on the 14th day in culture with adipogenic induction medium, as detected by Oil red 0 staining; B: osteogenic differentiation on the 21th day in culture with osteogenic induction medium, as detected by Alizarin red staining. Scale bars: $25 \mu \mathrm{m}$.

\section{Multipotential characteristics}

Takahashi's team demonstrated induced pluripotent stem cells (iPSCs) from mouse embryonic or adult fibroblasts by introducing four factors, Oct3/4, Sox2, c-Myc, and Klf4, under ES cell culture conditions [59]. It shows that pluripotent stem cells can be directly generated from fibroblast cultures by the addition of only a few defined factors. Moreover, iPSCs present several safety concerns such as the genetic and epigenetic aberrations they are carrying, as well as the potential risk for tumor formation [60]. Recently, advances in direct cell lineage conversion have suggested a potential solution to these issues. Moreover, as direct lineage conversion bypasses the pluripotent state, it could theoretically reduce the risk of tumorigenicity after transplantation [61].

Lineage reprogramming describes the conversion of differentiated cells directly into other somatic cell types. This general concept was first clearly established by the conversion of fibroblasts to skeletal myoblasts by the forced expression of MyoD in 1987, and was followed by more examples of lineage reprogramming, including conversion of $\mathrm{B}$ lymphocytes to macrophages, inner ear support cells to hair cells, exocrine pancreatic cells to endocrine $\beta$-cells, and fibroblasts to neurons [62]. A lineage reprogramming strategy for conversion of fibroblasts to cardiomyocytes was first reported by leda et al. in 2010 [63]. Qian et al. [64] described that a combination of three developmental transcription factors (i.e., Gata4, Mef2c and Tbx5) rapidly and efficiently reprogrammed post-natal cardiac or dermal fibroblasts directly into differentiated cardiomyocyte-like cells. Induced cardiomyocytes became binucleate, assembled sarcomeres and had cardiomyocyte-like gene expression. Song et al. [65] reported that addition of a fourth factor, Hand2, could increase the efficiency of the conversion. Some reports prove that expression of Ascl1, Brn2, and Myt1l efficiently converted mouse embryonic fibroblasts (MEFs) and postnatal fibroblasts into functional neurons (induced neurons, or iN cells) [66]. In this regard, the same strategy can be applied to human embryonic and postnatal fibroblasts. By overexpression of the transcription factors Ascl1, Brn2, and Myt1l, human fibroblasts were efficiently converted to functional neurons [67]. Zhang et al. [68] have reported that the conversion of human fibroblasts into retinal pigment epithelium lineage using defined sets of transcription factors.

Osteoblastic, chondrogenic, adipogenic differentiation from fibroblasts has also been described [69]. More recently, hepatocyte differentiation potential of adult human dermal fibroblasts was demonstrated in an in vivo model of liver injured immunodeficient mice [70]. Sandrine et al. [71] has published that human dermal fibroblasts (from adult skin or infant foreskin) and bone marrow mesenchymal stem cells (BM-MSCs) share in vitro morphology 
and many biological properties, but fibroblasts do not have the same capacity as BM-MSCs to differentiate into adipocytes and osteoblasts.

More recently, several reports have demonstrated that dermal fibroblasts are multipotent cells. Dermal skin-derived fibroblasts from rodent and human have been found to exhibit mesenchymal surface antigen immunophenotype and differentiation potential along the three main mesenchymal-derived tissues: bone, cartilage and fat [72, 73]. Rodent dermal fibroblast cell lines were examined for their mesenchymal potential [74-76]. Toma et al. [74] isolated skin-derived precursors (SKPs) from mouse dermis and characterized them as nestin and fibronectin positive, but not as vimentin or cytokeratin expressing cells. These cells could differentiate into cells of both neural and mesodermal lineages, like neurons, glia, smooth muscle cells and adipocytes. Crigler et al. [75] found a murine dermal skinderived subpopulation that had the capacity to differentiate into osteogenic, adipogenic, chondrogenic and myogenic cell lineages, and even into epidermal cell types.

Recently dermal fibroblasts have been proven to express the markers of mesenchymal stem cells and differentiate into osseous tissue, fat, cartilage, tendon, nerve, pancreatic islet and so on under certain induced medium. Our previous research shows that cardiac fibroblasts in neonate rats have similar capacity to differentiate into osteogenic and adipogenic cell lineages (Fig. 3).

These results give us a clue whether fibroblasts derived from all organs have multipotential characteristics and the ability to differentiate into other cell type.

\section{Conclusions}

Data illustrate extensive phenotypic heterogeneity among fibroblasts from different tissues and from a given tissue under different physiological conditions. In fact, cardiac fibroblasts comprise over $50 \%$ of all the cells in the heart $[8,15]$. Cardiac fibroblasts are fully differentiated somatic cells that provide support structure, secrete signals and contribute to scar formation upon cardiac damage. SAN pacemaker tissue has higher relative fibroblast content than ventricle, occupying some $45 \%$ to $75 \%$ of SAN volume in man $[77,78]$.

Although fibroblasts are the key component in the connective tissue, its function in the organism has been neglected. However, fibroblasts have the capacity to synthesize and remodel the extracellular matrix. In addition to their presumed role as scaffolding support, fibroblasts have been directly proven to play roles in regulating self-tolerance, organ development, wound healing, inflammation and fibrosis [6, 79-81]. Under normal physiological conditions, equilibrium between synthesis and degradation is maintained, and under pathological conditions, accumulated ECM results in tissue fibrosis. Inappropriate tissue repair and continued insult can result in chronic inflammation and eventually lead to fibrosis. At the cellular level, accumulation and persistence of myofibroblasts during tissue repair and healing has been proposed as a leading cause of fibrosis [82,83]. This process is associated with the transformation of granulation tissue into a hypertrophic scar with excessive production of ECM and ratification of the microvasculature.

More recent studies revealed that fibroblasts have much broader functions in any organism. These studies have suggested a "sentinel" role for fibroblasts that is intimately associated with the global response to mechanical, electrical, and chemical signals. Fibroblasts form a complex 3-D network within the connective tissue matrix that they occupy and play important roles in modulating the whole function of the organisms.

Fibroblasts show different functional phenotypes: migratory phenotype, proliferative phenotype, synthetic phenotype and contractile phenotype due to a variety of cytokines involved and in different conditions. Identification of specific molecular markers of fibroblasts should assist in continued efforts to understand this dynamic cell. Their stem cell-like characters and multipotential differentiation could provide new targets for in situ tissue repair and more abundant seed cells for cell therapy in various incurable pathological conditions. 


\section{Cellular Physiology Cell Physiol Biochem 2014;34:703-714 and Biochemistry \\ Chang/Li/Guo: Multipotential Differentiation Capacity of Fibroblasts}

\section{Acknowledgements}

We thank all members of the lab for sharing reagents and advice. This work was supported by a grant from the Brilliancy Talent Project (No. 084200510020) of Henan province, China.

\section{References}

1 Sisson TH, Maher TM, Ajayi IO, King JE, Higgins PD, Booth AJ, Sagana RL, Huang SK, White ES, Moore BB, Horowitz JC: Increased survivin expression contributes to apoptosis-resistance in IPF fibroblasts. Adv Biosci Biotechnol 2012;3:657-664.

2 Abdalla M, Goc A, Segar L, Somanath PR: Akt1 mediates alpha-smooth muscle actin expression and myofibroblast differentiation via myocardin and serum response factor. J Biol Chem 2013;288:3348333493.

3 Rodemann HP, Muller GA, Knecht A, Norman JT, Fine LG: Fibroblasts of rabbit kidney in culture. I. Characterization and identification of cell-specific markers. Am J Physiol 1991;261:F283-F291.

4 Cramer LP, Siebert M, Mitchison TJ: Identification of novel graded polarity actin filament bundles in locomoting heart fibroblasts: implications for the generation of motile force. J Cell Biol 1997;136:12871305.

-5 Phipps RP, Borrello MA, Blieden TM: Fibroblast heterogeneity in the periodontium and other tissues. J Periodontal Res 1997;32:159-165.

-6 Fries KM, Blieden T, Looney RJ, Sempowski GD, Silvera MR, Willis RA, Phipps RP: Evidence of fibroblast heterogeneity and the role of fibroblast subpopulations in fibrosis. Clin Immunol Immunopathol 1994;72:283-292.

7 Lekic PC, Pender N, McCulloch CA: Is fibroblast heterogeneity relevant to the health, diseases, and treatments of periodontal tissues? Crit Rev Oral Biol Med 1997;8:253-268.

8 Snider P, Standley KN, Wang J, Azhar M, Doetschman T, Conway SJ: Origin of cardiac fibroblasts and the role of periostin. Circ Res 2009;105:934-947.

-9 Coles B, Fielding CA, Rose-John S, Scheller J, Jones SA, O'Donnell VB: Classic interleukin-6 receptor signaling and interleukin- 6 trans-signaling differentially control angiotensin II-dependent hypertension, cardiac signal transducer and activator of transcription-3 activation, and vascular hypertrophy in vivo. Am J Pathol 2007;171:315-325.

10 Zhao XF, Wang DL, Wei ZR, Xue QY, Yu LM: The research of fibroblasts from human hypertrophic scar showing a mesenchymal stem cell phenotype and multilineage differentiation potentialities. Zhonghua Zheng Xing Wai Ke Za Zhi 2013;29:273-279.

11 Haniffa MA, Collin MP, Buckley CD, Dazzi F: Mesenchymal stem cells: the fibroblasts' new clothes? Haematologica 2009;94:258-263.

-12 Lin GL, Hankenson K D: Integration of BMP, Wnt, and notch signaling pathways in osteoblast differentiation. J Cell Biochem 2011;112:3491-3501.

-13 Junker JP, Sommar P, Skog M, Johnson H, Kratz G: Adipogenic, chondrogenic and osteogenic differentiation of clonally derived human dermal fibroblasts. Cells Tissues Organs 2010;191:105-118.

14 Kalluri R, Zeisberg M: Fibroblasts in cancer. Nat Rev Cancer 2006;6:392-401.

15 Chang HY, Chi JT, Dudoit S, Bondre C, van de Rijn M, Botstein D, Brown PO: Diversity, topographic differentiation, and positional memory in human fibroblasts. Proc Natl Acad Sci U S A 2002;99:1287712882.

16 Camelliti P, Borg TK, Kohl P: Structural and functional characterisation of cardiac fibroblasts. Cardiovasc Res 2005;65:40-51.

17 Corda S, Samuel JL, Rappaport L: Extracellular matrix and growth factors during heart growth. Heart Fail Rev 2000;5:119-130.

18 Abe R, Donnelly SC, Peng T, Bucala R, Metz CN: Peripheral blood fibrocytes: differentiation pathway and migration to wound sites. J Immunol 2001;166:7556-7562. 


\section{Cellular Physiology Cell Physiol Biochem 2014;34:703-714 and Biochemistry \\ Chang/Li/Guo: Multipotential Differentiation Capacity of Fibroblasts}

19 Goldsmith EC, Hoffman A, Morales MO, Potts JD, Price RL, McFadden A, Rice M, Borg TK: Organization of fibroblasts in the heart. Dev Dyn 2004;230:787-794.

20 Kohl P, Camelliti P, Burton FL, Smith GL: Electrical coupling of fibroblasts and myocytes: relevance for cardiac propagation. J Electrocardiol 2005;38:45-50.

-21 Zeisberg EM, Tarnavski O, Zeisberg M, Dorfman AL, McMullen JR, Gustafsson E, Chandraker A, Yuan X, Pu WT, Roberts AB, Neilson EG, Sayegh MH, Izumo S, Kalluri R: Endothelial-to-mesenchymal transition contributes to cardiac fibrosis. Nat Med 2007;13:952-961.

22 Banerjee I, Yekkala K, Borg TK, Baudino TA: Dynamic interactions between myocytes, fibroblasts, and extracellular matrix. Ann N Y Acad Sci 2006;1080:76-84.

-23 Ieda M, Tsuchihashi T, Ivey KN, Ross RS, Hong TT, Shaw RM, Srivastava D: Cardiac fibroblasts regulate myocardial proliferation through beta1 integrin signaling. Dev Cell 2009;16:233-244.

24 Soonpaa MH, Kim KK, Pajak L, Franklin M, Field LJ: Cardiomyocyte DNA synthesis and binucleation during murine development. Am J Physiol 1996;271:H2183-H2189.

25 Zak R: Development and proliferative capacity of cardiac muscle cells. Circ Res 1974;35:suppl II:17-26.

26 Nag AC: Study of non-muscle cells of the adult mammalian heart: a fine structural analysis and distribution. Cytobios 1980;28:41-61.

27 Camelliti P, Green CR, LeGrice I, Kohl P: Fibroblast network in rabbit sinoatrial node: structural and functional identification of homogeneous and heterogeneous cell coupling. Circ Res 2004;94:828-835. Kohl P: Cardiac cellular heterogeneity and remodelling. Cardiovasc Res 2004;64:195-197.

-29 Rossini M, Cheunsuchon B, Donnert E, Ma LJ, Thomas JW, Neilson EG, Fogo AB: Immunolocalization of fibroblast growth factor-1 (FGF-1), its receptor (FGFR-1), and fibroblast-specific protein-1 (FSP-1) in inflammatory renal disease. Kidney Int 2005;68:2621-2628.

- 30 Cossu G, Bianco P: Mesoangioblasts--vascular progenitors for extravascular mesodermal tissues. Curr Opin Genet Dev 2003;13:537-542.

- 31 Sartore S, Chiavegato A, Faggin E, Franch R, Puato M, Ausoni S, Pauletto P: Contribution of adventitial fibroblasts to neointima formation and vascular remodeling: from innocent bystander to active participant. Circ Res 2001;89:1111-1121.

-32 Sundberg C, Ivarsson M, Gerdin B, Rubin K: Pericytes as collagen-producing cells in excessive dermal scarring. Lab Invest 1996;74:452-466.

33 Perez-Pomares JM, Carmona R, Gonzalez-Iriarte M, Atencia G, Wessels A, Munoz-Chapuli R: Origin of coronary endothelial cells from epicardial mesothelium in avian embryos. Int J Dev Biol 2002;46:10051013.

-34 Abe R, Donnelly SC, Peng T, Bucala R, Metz CN: Peripheral blood fibrocytes: differentiation pathway and migration to wound sites. J Immunol 2001;166: 7556-7562

-35 Shrivastava A, Radziejewski C, Campbell E, Kovac L, McGlynn M, Ryan TE, Davis S, Goldfarb MP, Glass DJ, Lemke G, Yancopoulos: An orphan receptor tyrosine kinase family whose members serve as nonintegrin collagen receptors. Mol Cell 1997;1:25-34.

-36 Vogel W, Gish GD, Alves F, Pawson T: The discoidin domain receptor tyrosine kinases are activated by collagen. Mol Cell 1997;1:13-23.

- 37 Schlessinger J: Direct binding and activation of receptor tyrosine kinases by collagen. Cell 1997;91:869872.

- 38 Chin GS, Lee S, Hsu M, Liu W, Kim WJ, Levinson H, Longaker MT: Discoidin domain receptors and their ligand, collagen, are temporally regulated in fetal rat fibroblasts in vitro. Plast Reconstr Surg 2001;107:769-776.

39 Wang X, Khaidakov M, Ding Z, Dai Y, Mercanti F, Mehta JL: LOX-1 in the maintenance of cytoskeleton and proliferation in senescent cardiac fibroblasts. J Mol Cell Cardiol 2013; 60:184-190.

40 Zucchini A, Del Zotto G, Brando B, Canonico B: CD90. J Biol Regul Homeost Agents 2001;15:82-85.

41 Baglole CJ, Reddy SY, Pollock SJ, Feldon SE, Sime PJ, Smith TJ, Phipps RP: Isolation and phenotypic characterization of lung fibroblasts. Methods Mol Med 2005;117: 115-127.

-42 Hagood JS, Miller PJ, Lasky JA, Tousson A, Guo B, Fuller GM, Mslntosh JC: Differential expression of plateletderived growth factor-alpha receptor by Thy-1(-) and Thy-1(+) lung fibroblasts. Am J Physiol 1999;277: L218-L224.

43 Koumas L, King AE, Critchley HO, Kelly RW, Phipps RP: Fibroblast heterogeneity: existence of functionally distinct Thy 1+ and Thy 1- human female reproductive tract fibroblasts. A J Pathol 2001;159:925-935. 


\section{Cellular Physiology Cell Physiol Biochem 2014;34:703-714 and Biochemistry \\ Chang/Li/Guo: Multipotential Differentiation Capacity of Fibroblasts}

44 Koumas L, Smith TJ, Phipps RP: Fibroblast subsets in the human orbit: Thy-1+ and Thy-1- subpopulations exhibit distinct phenotypes. Eur J Immunol 2002;32:477-485.

45 Hudon-David F, Bouzeghrane F, Couture P, Thibault G: Thy-1 expression by cardiac fibroblasts: lack of association with myofibroblast contractile markers. J Mol Cell Cardiol 2007;42:991-1000.

-46 Kaufman J, Graf BA, Leung EC, Pollock SJ, Koumas L, Reddy SY, Blieden TM, Smith TJ, Phipps RP: Fibroblasts as sentinel cells: role of the CDcd40-CDcd40 ligand system in fibroblast activation and lung inflammation and fibrosis. Chest 2001;120:53S-55S.

47 Derdak S, Penney DP, Keng P, Felch ME, Brown D, Phipps RP: Differential collagen and fibronectin production by Thy 1+ and Thy 1- lung fibroblast subpopulations. Am J Physiol 1992;263:L283-L290.

-48 Sanders YY, Kumbla P, Hagood JS: Enhanced myofibroblastic differentiation and survival in Thy-1(-) lung fibroblasts. Am J Respir Cell Mol Biol 2007;36:226-235.

49 Strutz F, Okada H, Lo CW, Danoff T, Carone RL, Tomaszewski JE, Neilson EG: Identification and characterization of a fibroblast marker: FSP1. J Cell Biol 1995;130:393-405.

50 Mazzucchelli L: Protein S100A4: too long overlooked by pathologists? Am J Pathol 2002;160:7-13.

-51 Kraman M, Bambrough PJ, Arnold JN, Roberts EW, Magiera L, Jones JO, Gopinathan A, Tuveson DA, Fearon DT: Suppression of antitumor immunity by stromal cells expressing fibroblast activation protein-alpha. Science 2010;330:827-830.

52 Bouzeghrane F, Mercure C, Reudelhuber TL, Thibault, G: Alpha8beta1 integrin is upregulated in myofibroblasts of fibrotic and scarring myocardium. J Mol Cell Cardiol 2004;36:343-353.

-53 Thibault G, Lacombe MJ, Schnapp LM, Lacasse A, Bouzeghrane F, Lapalme G: Upregulation of alpha(8) beta(1)-integrin in cardiac fibroblast by angiotensin II and transforming growth factor-beta1. Am J Physiol Cell Physiol 2001;281:C1457-C1467.

-54 Horwitz EM, Le Blanc K, Dominici M, Mueller I, Slaper-Cortenbach I, Marini FC, Deans RJ, Krause DS, Keating A; International Society for Cellular Therapy: Clarification of the nomenclature for MSC: The International Society for Cellular Therapy position statement. Cytotherapy 2005;7:393-395.

-55 Dominici M, Le Blanc K, Mueller I, Slaper-Cortenbach I, Marini F, Krause D, Deans R, Keating A, Prockop Dj, Horwitz E: Minimal criteria for defining multipotent mesenchymal stromal cells. The International Society for Cellular Therapy position statement. Cytotherapy 2006;8:315-317.

-56 Saeed H, Taipaleenmaki H, Aldahmash AM, Abdallah BM, Kassem M: Mouse embryonic fibroblasts (MEF) exhibit a similar but not identical phenotype to bone marrow stromal stem cells (BMSC). Stem Cell Rev 2012;8:318-328.

-57 Szabo E, Rampalli S, Risueňo RM, Schnerch A, Mitchell R, Fiebig-Comyn A, Levadoux-Martin M, Bhatia M: Direct conversion of human fibroblasts to multilineage blood progenitors. Nature 2010;468:521-526.

-58 Cauffman G, Van de Velde H, Liebaers I, Van Steirteghem A: Oct-4 mRNA and protein expression during human preimplantation development. Mol Hum Reprod 2005;11:173-181.

-59 Takahashi K, Yamanaka S: Induction of pluripotent stem cells from mouse embryonic and adult fibroblast cultures by defined factors. Cell 2006;126:663-676.

-60 Panopoulos AD, Ruiz S, Izpisua Belmonte JC: iPSCs: induced back to controversy. Cell Stem Cell 2011;8:347348.

61 Ben-David U, Benvenisty N: The tumorigenicity of human embryonic and induced pluripotent stem cells. Nat Rev Cancer 2011;11:268-277.

62 Asuelime GE, Shi Y: A case of cellular alchemy: lineage reprogramming and its potential in regenerative medicine. J Mol Cell Biol 2012;4:190-196.

-63 Ieda M, Fu JD, Delgado-Olguin P, Vedantham V, Hayashi Y, Bruneau BG, Srivastava D: Direct reprogramming of fibroblasts into functional cardiomyocytes by defined factors. Cell 2010;142:375-386.

-64 Qian L, Huang Y, Spencer CI, Foley A, Vedanthan V, Liu L, Conway SJ, Fu JD, Srivastava D: In vivo reprogramming of murine cardiac fibroblasts into induced cardiomyocytes. Nature 2012;485:593-598.

65 Song K, Nam YJ, Luo X, Qi X, Tan W, Huang GN, Acharya A, Smith CL, Tallquist MD, Neilson EG, Hill JA, Bassel-Duby R, Olson EN: Heart repair by reprogramming non-myocytes with cardiac transcription factors. Nature 2012;485:599-604.

-66 Vierbuchen T, Ostermeier A, Pang ZP, Kokubu Y, Sudhof TC, Wernig M: Direct conversion of fibroblasts to functional neurons by defined factors. Nature 2010;463:1035-1041. 


\section{Cellular Physiology $\quad$ Cell Physiol Biochem 2014;34:703-714

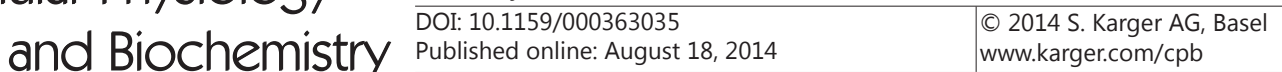 \\ Chang/Li/Guo: Multipotential Differentiation Capacity of Fibroblasts}

67 Pfisterer U, Kirkeby A, Torper O, Wood J, Nelander J, Dufour A, Björklund A, Lindvall O, Jakobsson J, Parmar M: Direct conversion of human fibroblasts to dopaminergic neurons. Proc Natl Acad Sci U S A 2011;108:10343-10348.

68 Zhang K, Liu GH, Yi F, Montserrat N, Hishida T, Rodriguez Esteban C, Izpisua Belmonte JC: Direct conversion of human fibroblasts into retinal pigment epithelium-like cells by defined factors. Protein Cell 2014;5:4858.

69 Haniffa MA, Wang XN, Holtick U, Rae M, Isaacs JD, Dickinson AM, Hilken CM, Collin MP: Adult human fibroblasts are potent immunoregulatory cells and functionally equivalent to mesenchymal stem cells. J Immunol 2007;179:1595-1604.

70 Lysy PA, Smets F, Sibille C, Najimi M, Sokal EM: Human skin fibroblasts: From mesodermal to hepatocytelike differentiation. Hepatology 2007;46:1574-1585.

-71 Cappellesso-Fleury S, Puissant-Lubrano B, Apoil PA, Titeux M, Winterton P, Casteilla L, Bourin P, Blancher A: Human fibroblasts share immunosuppressive properties with bone marrow mesenchymal stem cells. J Clin Immunol 2010;30:607-619.

-72 Lorenz K, Sicker M, Schmelzer E, Rupf T, Salvetter J, Schulz-Siegmund M, Bader A: Multilineage differentiation potential of human dermal skin-derived fibroblasts. Exp Dermatol 2008;17:925-932.

73 Crigler L, Robey RC, Asawachaicharn A, Gaupp D, Phinney DG: Human mesenchymal stem cell subpopulations express a variety of neuro-regulatory molecules and promote neuronal cell survival and neuritogenesis. Exp Neurol 2006;198:54-64.

74 Toma JG, Akhavan M, Fernandes KJ, Barnabé-Heider F, Sadikot A, Kaplan DR, Miller FD: Isolation of multipotent adult stem cells from the dermis of mammalian skin. Nat Cell Biol 2001;3:778-784.

75 Crigler L, Kazhanie A, Yoon TJ, Zakhari J, Taylor B, Virador VM: Isolation of a mesenchymal cell population from murine dermis that contains progenitors of multiple cell lineages. FASEB J 2007;21:2050-2063.

-76 French MM, Rose S, Canseco J, Athanasiou KA: Chondrogenic differentiation of adult dermal fibroblasts. Ann Biomed Eng 2004;32:50-56.

77 Shiraishi I, Takamatsu T, Minamikawa T, Onouchi Z, Fujita S: Quantitative histological analysis of the human sinoatrial node during growth and aging. Circulation 1992;85:2176-2184.

78 Camelliti P, Green CR, LeGrice I, Kohl P: Fibroblast network in rabbit sinoatrial node: structural and functional identification of homogeneous and heterogeneous cell coupling. Circ Res 2004;94: 828-835

79 Mebius, RE: Organogenesis of lymphoid tissues. Nat Rev Immunol 2003;3:292-303.

80 Parsonage G, Filer AD, Haworth O, Nash GB, Rainger GE, Salmon M, Buckley CD: A stromal address code defined by fibroblasts. Trends Immunol 2005; 26:150-156.

81 Serhan CN, Brain SD, Buckley CD, Gilroy DW, Haslett C, O'Neil LA, Perretti M, Rossi AG, Wallace JL: Resolution of inflammation: state of the art, definitions and terms. FASEB J 2007;21:325-332.

82 Desmouliere A, Darby IA, Gabbiani G: Normal and pathologic soft tissue remodeling: role of the myofibroblast, with special emphasis on liver and kidney fibrosis. Lab Invest 2003;83:1689-1707.

83 Kramann R, DiRocco DP, Humphreys BD: Understanding the origin, activation and regulation of matrixproducing myofibroblasts for treatment of fibrotic disease. J Pathol 2013;231:273-289. 